\title{
The Efficiency of Bimodal Silica as a Carbon Dioxide Adsorbent for Natural Gas Treatment
}

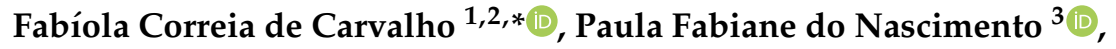 \\ Márcio Rodrigo Oliveira de Souza ${ }^{1}$ and Antonio Souza Araujo ${ }^{1}$ \\ 1 Postgraduate Program in Petroleum Science and Engineering, Federal University of Rio Grande do Norte, \\ Natal 59078-970, RN, Brazil; marciorodrigo2006@hotmail.com (M.R.O.d.S.); araujo.ufrn@gmail.com (A.S.A.) \\ 2 SENAI Institute of Innovation in Renewable Energy, Sustainability Laboratory, Natal 59064-164, RN, Brazil \\ 3 Postgraduate Program in Chemical Engineering, Federal University of Rio Grande do Norte, Natal \\ 59078-970, RN, Brazil; paula_fabiane@hotmail.com \\ * Correspondence: fabiola_correia@hotmail.com; Tel./Fax: +55-849-992-979-23
}

Received: 17 January 2020; Accepted: 18 February 2020; Published: 4 March 2020

\begin{abstract}
Natural gas (NG) production in Brazil has shown a significant increase in recent years. Oil and natural gas exploration and refining activities indicate circa $86 \%$ carbon dioxide content in NG, representing a serious problem for environmental issues related to greenhouse gas emissions and increases in global warming. New technologies using $\mathrm{CO}_{2}$ capture materials have been shown to be more efficient than conventional processes. In this work, a bimodal meso-macroporous silica adsorbent for $\mathrm{CO}_{2}$ adsorption in NG was synthesized and evaluated as a promising material for use in natural gas treatment systems, as silica has specific textural properties that facilitate the capture and storage of this gas. The adsorbent was obtained from silica via the hydrothermal method with n-dodecane emulsion and characterized by X-ray diffraction, scanning electron microscopy, infrared spectroscopy, and the BET specific surface area. Adsorption capacity tests were performed for $\mathrm{CO}_{2}$, methane, and their mixtures by the gravimetric method, demonstrating that the adsorbent was selective for $\mathrm{CO}_{2}$ and obtained a good adsorption capacity. The experimental values obtained were compared and adjusted to the models of Langmuir and Freundlich. Thus, the bimodal silica adsorbent developed in this research proved to be excellent for $\mathrm{CO}_{2}$ adsorption and is a promising material for the treatment of NG.
\end{abstract}

Keywords: carbon dioxide adsorption; methane; natural gas; silica; hybrid materials

\section{Introduction}

Natural gas (NG) production in Brazil has shown a significant increase in recent years [1] and comprises a mixture of gaseous hydrocarbons, mainly methane, followed by ethane, propane, butane, and heavier hydrocarbons. In addition to these hydrocarbons, other compounds may be present, such as water, nitrogen, hydrogen sulfide $\left(\mathrm{H}_{2} \mathrm{~S}\right)$, carbon dioxide $\left(\mathrm{CO}_{2}\right)$, other sulfur compounds, and impurities, with $\mathrm{H}_{2} \mathrm{~S}$ and $\mathrm{CO}_{2}$ being the most common. These problems, in addition to causing corrosion and the leakage of pipes, decrease the quality of the fuel, necessitating the effective treatment of NG to remove these compounds [2].

Oil and natural gas exploration and refining activities account for and estimated $86 \%$ of $\mathrm{CO}_{2}$ emissions [3-5] and therefore represent a serious problem for environmental issues related to greenhouse gas emissions and increased global warming, as $\mathrm{CO}_{2}$ is the main cause of anthropogenic global warming. For the NG found in Brazilian pre-salt reserves, these data are even more concerning, as this NG has a higher concentration of $\mathrm{CO}_{2}$, with reserves that have a concentration above $70 \%$; for these cases, the 
gas produced is reinjected into the fields as a method of oil recovery [6-8]. Thus, the development of cost-effective $\mathrm{CO}_{2}$-capturing materials is of great importance to the oil industry.

$\mathrm{CO}_{2}$ adsorption using porous solid materials is an alternative to using liquid amines, a process used today in the industry, with zeolites [9], coordinating polymers, activated carbon, and mesoporous silicas [10] the most commonly used substances for this purpose. The first study on silica adsorption was reported in 1995 [11], concluding that silica-based adsorbents have potential for $\mathrm{CO}_{2}$ adsorption. After that study, a wide variety of solids, especially mesoporous silicas, were used for the capture and separation of $\mathrm{CO}_{2}$ [12-17] and synthesized by the hydrothermal method [18,19]. For adsorption tests, the gravimetric method has been widely used in the literature and consists of measuring the adsorbent mass as the adsorption phenomenon occurs [20-24].

Therefore, this research has aimed to synthesize a $\mathrm{CO}_{2}$ adsorbent material from bimodal silica via the hydrothermal method to obtain an adsorbent silica with an ordered structure of the meso-macroporous type. After synthesis, this material was characterized to present the textural properties of the bimodal silica. Then, the adsorbent was tested for its adsorption capacity of $\mathrm{CO}_{2}, \mathrm{CH}_{4}$, and mixtures $(12 \%, 25 \%, 35 \%$, and $50 \%$ in $\mathrm{Vol})$ of $\mathrm{CO}_{2}$ in $\mathrm{CH}_{4}$ by the gravimetric method, revealing $\mathrm{CO}_{2}$ selectivity and adsorption capacity.

\section{Materials and Methods}

\subsection{Synthesis of the Adsorbent}

Bimodal silica was synthesized by the hydrothermal method based on the procedure reported in [23]. The materials used were Sodium Silicate, Decan, Hydrochloric Acid, and distilled water as a solvent.

Firstly, $20 \mathrm{~mL}$ of water and $3 \mathrm{~g}$ of sodium silicate were mixed and stirred continuously at $50{ }^{\circ} \mathrm{C}$ to facilitate interactions with the surfactant. A total of $10 \mathrm{~mL}$ of decane was then added dropwise to the solution under constant stirring until the desired dispersed phase was obtained. Having formed the emulsion, $5 \mathrm{~mL}$ of concentrated hydrochloric acid was added to initiate the silicate hydrolysis reaction. The resulting mixture was stirred for half an hour and introduced into a coated Teflon vessel for hydrothermal treatment at $100{ }^{\circ} \mathrm{C}$ for $24 \mathrm{~h}$ to allow the silicate to polymerize in the aqueous solution in the presence of the emulsion phase, thereby producing an ordered mesoporous structure containing macropores.

At the end of the hydrothermal treatment, the material obtained was vacuum filtered and then taken to the oven for drying at $120^{\circ} \mathrm{C}$. After drying, the material was washed with a mixture of ethanol and $1 \mathrm{~mol} \cdot \mathrm{L}^{-1}$ hydrochloric acid solution (1:1) followed by new hydrochloric acid filtration to remove the $\mathrm{Na}^{+}$ion residues from the sodium silicate. This material was calcined at $550{ }^{\circ} \mathrm{C}$ for $5 \mathrm{~h}$ to remove the residual surfactant to yield a fine white powdery material. The calcination process was performed in an EDGCON 3P muffle furnace, using a programmed temperature of $10^{\circ} \mathrm{C} \cdot \mathrm{min}^{-1}$ under a dynamic nitrogen atmosphere of $60 \mathrm{~mL} \cdot \mathrm{min}^{-1}$ until reaching $550{ }^{\circ} \mathrm{C}$ and was kept at this temperature for $4 \mathrm{~h}$. Then, the gas was replaced by an oxidizing atmosphere and held for an additional $1 \mathrm{~h}$.

\subsection{Characterization}

After synthesis, the adsorbent was characterized by X-ray diffraction (XRD), scanning electron microscopy (SEM), specific surface area (BET), and infrared absorption spectroscopy for Fourier Transform (FT-IR) in order to determine its textural properties.

XRD analyses were performed by the powder method on a Bruker D2Phaser apparatus in the 2-theta range: 1-10 (Low) and 5-70 (High).

The specific surface area analyses were performed using Micromeritics ASAP 2020 equipment via the BET method, which consists of the adsorption of $\mathrm{N}_{2}$ at a temperature of $77 \mathrm{~K}$ from the adsorption and desorption isotherms. 
Scanning electron microscopy (SEM) images were obtained with magnification to allow the visualization of materials at the nanometer scale, and the sample was previously metallized, aiming to make it conductive. The micrographs were obtained using Tescan equipment, model Vega 3.

Fourier Transform Infrared (FT-IR) analysis was performed using the IRAffinity ${ }^{-1}$ model manufactured by Shimadzu in a range from 4000 to $400 \mathrm{~cm}^{-1}$.

\subsection{Obtaining the Adsorption Isotherms}

The determination of the adsorption capacity of the adsorbent materials by the gravimetric method involved measuring the adsorbent mass as the adsorbate adsorption phenomenon occurred and was performed in four steps: measurement of the effect of no sample thrust, sample reactivation, measurement of the thrust effect with the sample, and measurement of the adsorbed mass.

For the proposed study, the static adsorption process of the pure gases $\mathrm{CO}_{2}$ and $\mathrm{CH}_{4}$ and their mixtures $\left(12 \%, 25 \%, 36 \%\right.$, and $50 \% \mathrm{CO}_{2}$ in $\left.\mathrm{CH}_{4}\right)$ was carried out on a Rubotherm magnetic suspension scale, installed at the SENAI Institute of Innovation in Renewable Energy (ISI-ER).

The experimental values obtained were compared and adjusted to the models proposed in the literature (Langmuir and Freundlich) [24].

The Langmuir model considers that the adsorption sites are energetically equivalent, that each molecule of the adsorbate takes one site only, and that they do not interact with each other. This approach can be modelled as follows:

$$
q_{e}=\frac{q_{m} \cdot b \cdot C_{p}}{1+b \cdot C_{p}}
$$

where $q_{e}$ is the concentration of the adsorbate in equilibrium with the fluid phase (mol/g), $q_{m}$ is the maximum adsorption capacity $(\mathrm{mol} / \mathrm{g}), b$ is the equilibrium constant $(\mathrm{L} / \mathrm{mol})$, and $C_{P}$ is the equilibrium concentration of the adsorbate $(\mathrm{g} / \mathrm{L})$, which can be determined by the ideal gas law:

$$
C p=\frac{P \cdot M M}{R T}
$$

where $P$ is the system pressure $(\mathrm{Pa}), M M$ is the adsorbate molecular mass $(\mathrm{g} / \mathrm{mol}), T$ is the adsorption temperature $(K)$, and $R$ is the ideal gas constant $(8.314 \mathrm{~L} \cdot \mathrm{kPa} /(\mathrm{mol} \cdot \mathrm{K}))$.

The Freundlich model describes equilibrium on heterogeneous surfaces and allows a logarithmic distribution of the active sites, thereby offering a useful treatment when there is no interaction between the adsorbate molecules; this model can be expressed as follows:

$$
q_{e}=K_{e} \cdot C_{p}{ }^{1 / n}
$$

where $K_{e}$ is the adsorption capacity of the solid (L/g), $1 / n$ is a measure of the adsorption intensity, and $q e$ is the concentration of the adsorbate in the solid phase in equilibrium with the fluid phase. Both $\mathrm{Ke}$ and $n$ were determined experimentally.

\section{Results and Discussions}

\subsection{Characterization of the Adsorbents Obtained}

Figure 1 presents $X$-ray diffractograms of the obtained silica at a low angle (1a; 1 to $\left.10^{\circ}\right)$ and at a high angle $\left(1 \mathrm{~b} ; 15\right.$ to $\left.60^{\circ}\right)$. 

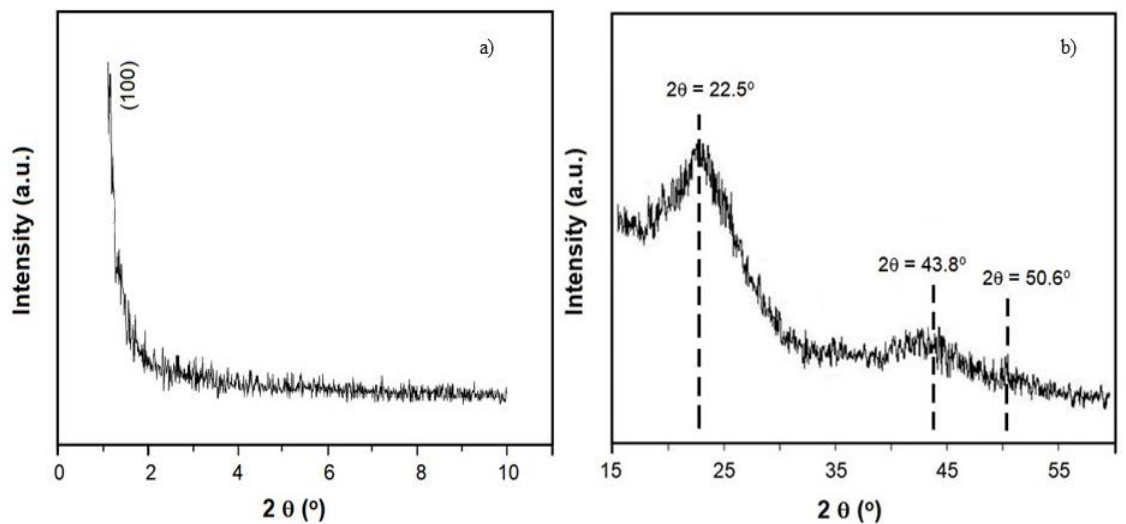

Figure 1. X-ray diffractograms of the bimodal silica at a low angle (a) and a high angle (b).

The results revealed the presence of an acute peak at a low angle and other peaks at a high angle, indicating that silica occurs in a bimodal form. This material can be considered a type of active silica, as it exists in a more reactive phase than the crystalline phase of silica, which do not have peaks that show the long-range order characteristics of the crystal.

In Figure $1 \mathrm{a}$, a peak was observed at about $2 \theta=1.2^{\circ}$, which was attributed to the plane (100). The shape of the peak shows that an ordered phase of silica was obtained. In Figure $1 \mathrm{~b}$, a high intensity Bragg angle centered at $2 \theta=22.5^{\circ}$ was also recorded. This peak is typical of amorphous silica; however, the presence of two other peaks at $2 \theta=43.8^{\circ}$ and $2 \theta=50.6^{\circ}$ indicates the presence of crystallographic phases attributed to alpha-cristobalite and quartz, which are obtained after calcination of the silica (amorphous silica) [25].

Figure 2a,b shows the particle aggregates and particle distribution, respectively. Most $\mathrm{SiO}_{2}$ particles are observed in the 50 to $200 \mathrm{~nm}$ size range, thereby characterizing the presence of nanoscale porous materials. These particles have a tendency to form mesoporous aggregates. Macropores are observed between the particle aggregates. For better verification of the porosity of the materials, a computational image processing resource was used; this resource verified the presence of mesoporous and microporous silica, clearly showing the bimodal silica porosity system.
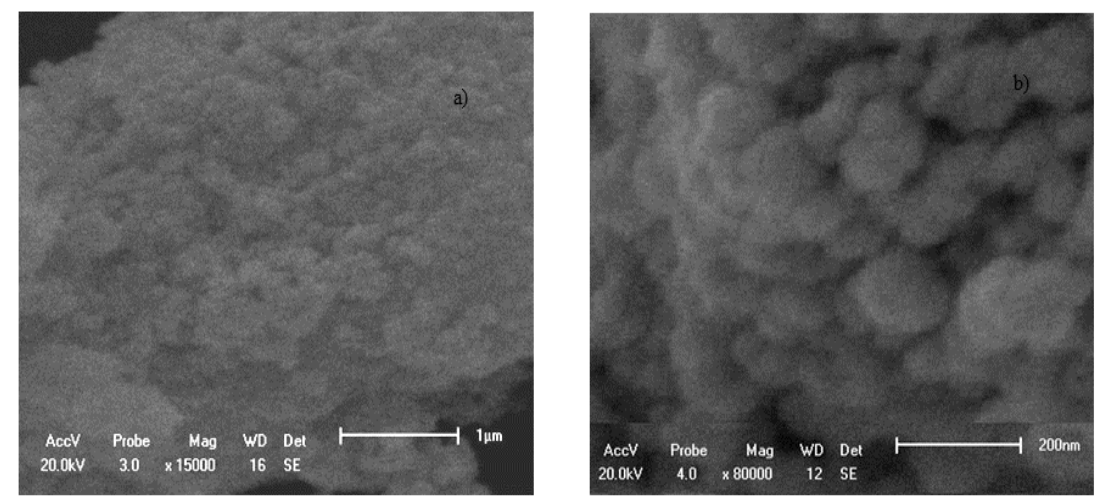

Figure 2. SEM image of the bimodal silica showing particle aggregates (a) and the particle distribution (b).

Figure 3 shows the mesoporous and macroporous ordering in the bimodal silica. Analyzing the image, it appears that the materials obtained feature typically amorphous silica, with an internal structure consisting of structural blocks connected to each other. Despite this amorphous material, this ordering is typically observed due to the nature of the chemical bonding of the silica (-O-Si-O-), with the mesoporous silica forming typically linear cylinder and the macropores originating from interconnected cracks and crevices (Slit Pores). These chemical bonds allow the bimodal silica to react 
with other materials around it, facilitating a better adsorption capacity and indicating characteristics beneficial for gas capture and storage.

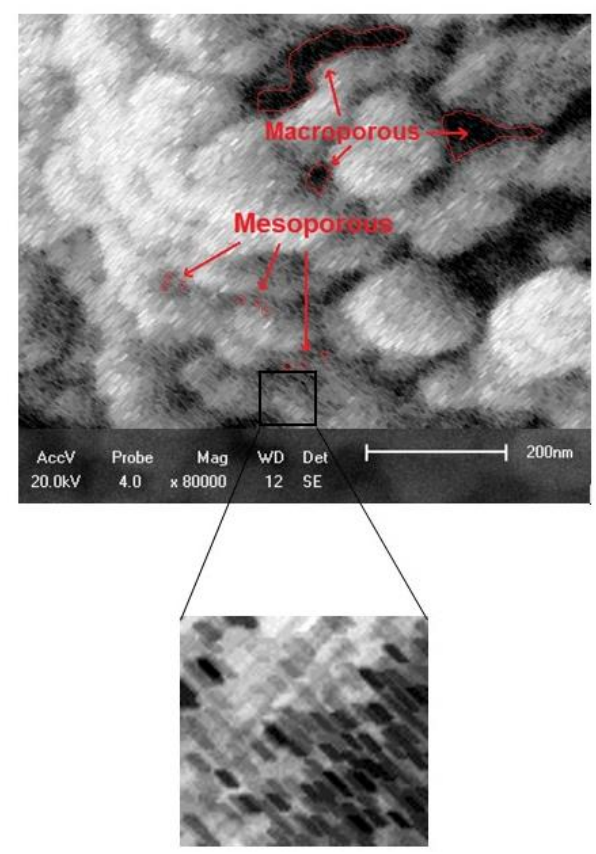

Figure 3. Mesopore and macropore ordering in the bimodal silica.

According to the BET equation, Nitrogen adsorption analysis at $77 \mathrm{~K}$ obtained the adsorption isotherm, which is shown in Figure 4.

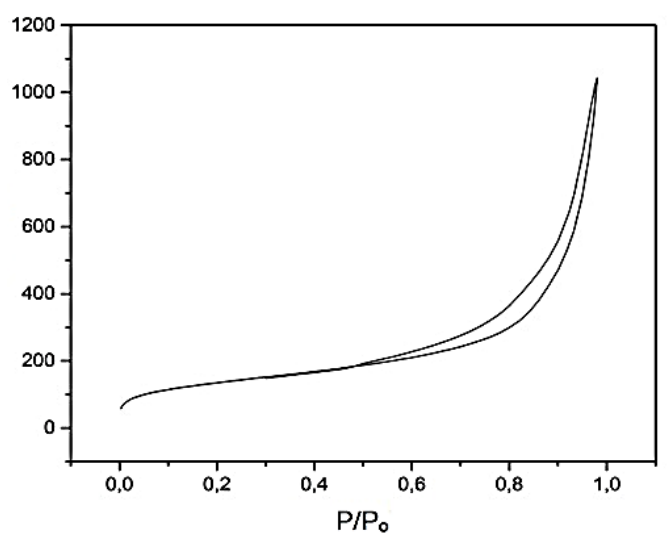

Figure 4. Nitrogen Adsorption Isotherm for the Bimodal Silica (obtained at $77 \mathrm{~K}$ ).

The specific area obtained was equivalent to $230 \mathrm{~m}^{2} / \mathrm{g}$, presenting a typical value for ordered silica. The bimodal silica demonstrates a good desorption capacity at low relative pressures $\left(\mathrm{P} / \mathrm{P}_{0}<0.3\right)$, which remain almost constant in a relative pressure range from 0.5 to 0.8 , with a positive slope in the curve at relative pressures greater than 0.8 . This behavior is characteristic of adsorbents that have a uniform pore distribution [26] and presents meso-macroporous pores [15].

During the formation of the $\mathrm{N}_{2}$ adsorption isotherms, two distinct events were observed. The first event shows the amount of gas adsorbed with increasing relative pressure, while the other represents the amount of gas adsorbed in the reverse process. These events are characteristic of solids with large pore sizes (meso and macro), where the adsorbate $\left(\mathrm{N}_{2}\right)$ evaporation process that occurs inside the pores is different from capillary condensation, with monolayer formation followed by adsorption 
from multilayer to isotherm inflection and saturation (which, for bimodal silica, is type I + IV [15,22], according to the IUPAC classification [27]).

By obtaining the results of the nitrogen adsorption and desorption data analysis, it was possible to identify the pore size distribution, as shown in Figure $5 \mathrm{a}, \mathrm{b}$, for porosity at $2-5 \mathrm{~nm}$ and $5-50 \mathrm{~nm}$, respectively.
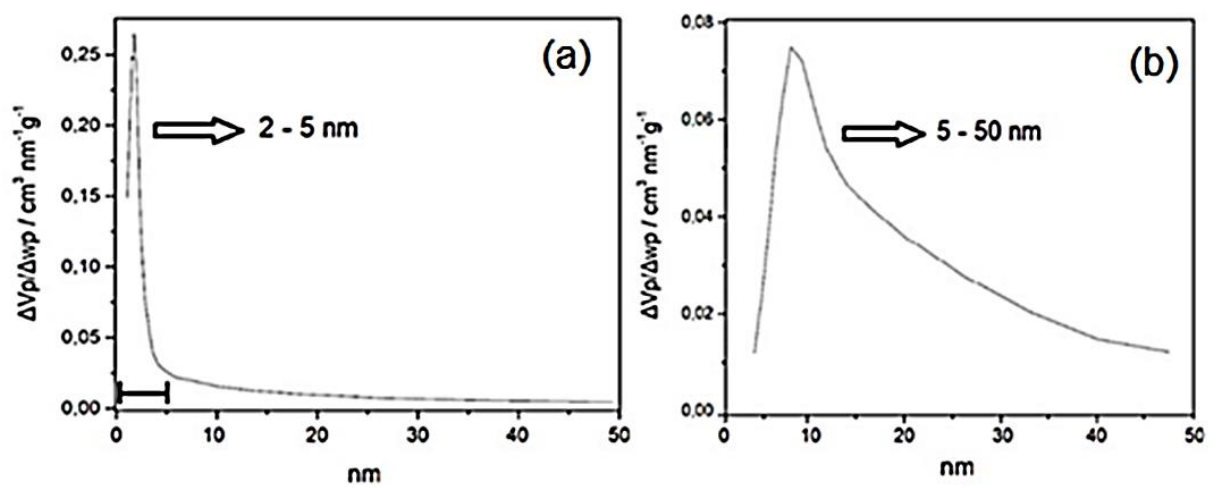

Figure 5. Pore volume distribution for bimodal silica in the range of $2-5 \mathrm{~nm}(\mathbf{a})$ and $5-50 \mathrm{~nm}(\mathbf{b})$.

In order to verify the chemical bonds in silica, specifically for silane groups, surface water, and the stretches and deformations of the $\mathrm{O}-\mathrm{Si}-\mathrm{O}$ bonds in silica $\left(\mathrm{SiO}_{2}\right)$, the infra-red (FT-IR) spectrum of the bimodal silica was analyzed (shown in Figure 6).

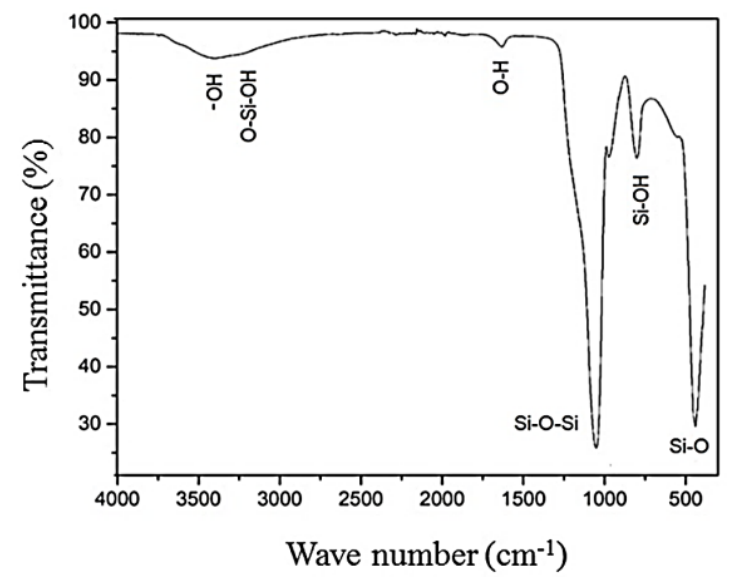

Figure 6. Infrared absorption spectrum of the bimodal silica.

The FT-IR spectrum obtained in the range of 4000 to $400 \mathrm{~cm}^{-1}$ shows an absorption band at $3435 \mathrm{~cm}^{-1}$ caused by the stretching of the $-\mathrm{OH}$ bonds in the superficial $\mathrm{H}_{2} \mathrm{O}$ molecules. The deformation band of this vibration was observed at $1632 \mathrm{~cm}^{-1}(\mathrm{H}-\mathrm{OH})$. The shoulder found at about $3245 \mathrm{~cm}^{-1}$ can be attributed to the vibrations of the silanol ( $\mathrm{Si}-\mathrm{OH})$ stretching present in the amorphous silica's structure. The presence of the $\mathrm{Si}-\mathrm{OH}$ group was proven to be a consequence of water bound to the silica. The strong band observed at $1080 \mathrm{~cm}^{-1}$ with a shoulder at about $1190 \mathrm{~cm}^{-1}$ is attributed to the asymmetric vibrations of the internal and external tetrahedra of the Si-O-Si bonds. The IR band at $950 \mathrm{~cm}^{-1}$ may be assigned to the silanol groups. The gait at about $800 \mathrm{~cm}^{-1}$ is attributed to the symmetrical stretching of the Si-O-Si groups, while the gait observed at $475 \mathrm{~cm}^{-1}$ is due to O-Si-O strain vibrations. 


\subsection{Adsorption Isotherms}

The adsorption capacity of $\mathrm{CO}_{2} / \mathrm{CH}_{4}$ and its mixtures was determined by equilibrium isotherms obtained in the static adsorption process and named according to the pure gases and the $\mathrm{CO}_{2}$ composition in the gas mixtures with $\mathrm{CH}_{4}$, as shown in Table 1.

Table 1. Names of the adsorption isotherms.

\begin{tabular}{cc}
\hline GAS & NAME \\
\hline Pure Gas $\mathrm{CO}_{2}$ & $\mathrm{SiCO}_{2}$ \\
Mixture $12 \% \mathrm{CO}_{2}+\mathrm{CH}_{4}$ (Balance) & $\mathrm{Si12}$ \\
Mixture $25 \% \mathrm{CO}_{2}+\mathrm{CH}_{4}$ (Balance) & $\mathrm{Si} 25$ \\
Mixture $36 \% \mathrm{CO}_{2}+\mathrm{CH}_{4}$ (Balance) & $\mathrm{Si36}$ \\
Mixture $50 \% \mathrm{CO}_{2}+\mathrm{CH}_{4}$ (Balance) & $\mathrm{Si50}$ \\
Pure Gas $\mathrm{CH}_{4}$ & $\mathrm{SiCH}_{4}$ \\
\hline
\end{tabular}

In order to study the selectivity of bimodal silica for $\mathrm{CO}_{2}$, the adsorption results of pure $\mathrm{CO}_{2}$ and $\mathrm{CH}_{4}$ gases were evaluated, as shown in Figure 7.

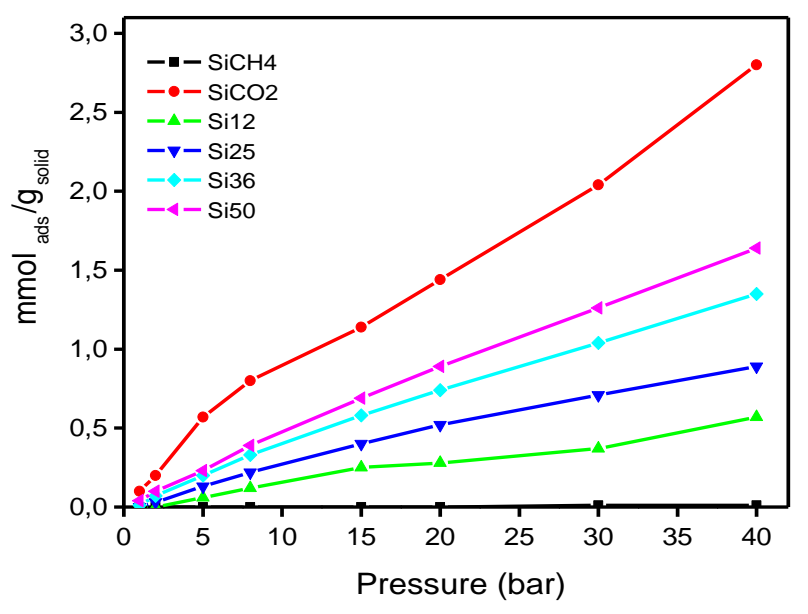

Figure 7. Adsorption isotherms.

According to Figure 7, bimodal silica selectivity is notorious for $\mathrm{CO}_{2}$ capture and not for $\mathrm{CH}_{4}$, since it presented practically zero adsorption capacity $(0.02 \mathrm{mmol} / \mathrm{g})$ for this gas. This information is extremely important in the development of technologies for the treatment of NG, since the adsorption efficiency for the removal of contaminant $\mathrm{CO}_{2}$ has been reached, making it possible to realize the parameters necessary for commercialization. In order to study the efficiency of bimodal silica as a $\mathrm{CO}_{2}$ adsorbent for pre-salt NG treatment, the compositions of $12 \%, 25 \%, 36 \%$, and $50 \% \mathrm{CO}_{2}$ in $\mathrm{CH}_{4}$ (balance) were evaluated, as well as the influence of the pressure of these adsorption gases.

For $\mathrm{CO}_{2}$ adsorption in the gaseous composition, the expected result was obtained, with an increase in the mmol amount of $\mathrm{CO}_{2}$ adsorbed by the adsorbent and an increase of this gas in the gas mixture.

Another relevant aspect is related to the influence of gas pressure on adsorption. It is evident that the adsorbed mass increases with an increase in system pressure. These results show the need to perform NG treatment via adsorption at higher pressures, which demonstrates the viability of the sample for the treatment of pre-salt NG.

We also observed a faster adsorption at pressures up to 5 bar, presenting behavior close to the linear model due to the greater availability of the active sites to these pressures. The adsorption results (in mmol) for the $\mathrm{CO}_{2} / \mathrm{g}$ adsorbent for bimodal silica are shown in Table 2. 
Table 2. $\mathrm{CO}_{2}$ adsorption capacities obtained at different pressures.

\begin{tabular}{cccccc}
\hline \multirow{2}{*}{ Presssure (Bar) } & \multicolumn{5}{c}{ Adsorption of $\mathbf{C O}_{\mathbf{2}}(\mathbf{m m o l} / \mathbf{g})$} \\
\cline { 2 - 6 } & $\mathbf{S i C O}_{\mathbf{2}}$ & $\mathbf{S i 1 2}$ & $\mathbf{S i 2 5}$ & $\mathbf{S i 3 6}$ & $\mathbf{S i 5 0}$ \\
\hline 1 & 0.10 & 0.00 & 0.00 & 0.01 & 0.04 \\
2 & 0.20 & 0.00 & 0.03 & 0.07 & 0.10 \\
5 & 0.57 & 0.06 & 0.13 & 0.20 & 0.23 \\
8 & 0.80 & 0.12 & 0.22 & 0.33 & 0.39 \\
15 & 1.14 & 0.25 & 0.40 & 0.58 & 0.69 \\
20 & 1.44 & 0.28 & 0.52 & 0.74 & 0.89 \\
30 & 2.04 & 0.37 & 0.71 & 1.04 & 1.26 \\
40 & 2.80 & 0.57 & 0.89 & 1.35 & 1.64 \\
TOTAL & 9.08 & 1.66 & 2.90 & 4.32 & 5.25 \\
\hline
\end{tabular}

Based on the data obtained, the bimodal silica presented very satisfactory results for $\mathrm{CO}_{2}$ adsorption at both low and high pressures due to silica's textural properties, which offer a high surface area containing meso and macropores. In addition, the material has reactivity with other materials around it, facilitating better adsorption capacity.

In order to evaluate the efficiency of bimodal silica in relation to other adsorbents, the adsorption results were compared with those of the literature. To evaluate low pressure adsorbents, Barbosa (2013) [19] and Dantas (2016) [17] developed their studies with commercial solid adsorbents, as shown in Table 3.

Table 3. $\mathrm{CO}_{2}$ adsorption capacities at low pressures.

\begin{tabular}{ccc}
\hline Adsorbents & Adsorption of $\left.\mathbf{C O}_{\mathbf{2}} \mathbf{( m m o l \cdot g} \mathbf{m}^{\mathbf{1}}\right)$ & Reference \\
\hline $\mathrm{SiCO}_{2}$ & 0.1 & Author \\
$\mathrm{MCM}-41$ & 0.18 & Barbosa (2013) \\
$\mathrm{SBA}-15$ & 0.64 & Barbosa (2013) \\
$10 \%$ E-SBA16 & 1.07 & Dantas (2016) \\
$30 \%$ E-SBA16 & 0.82 & Dantas (2016) \\
$50 \%$ E-SBA16 & 0.77 & Dantas (2016) \\
\hline
\end{tabular}

According to the results shown in Table 3, the $\mathrm{CO}_{2}$ adsorption capacity of bimodal silica at low pressures, when compared to the commercially available pure adsorbent materials used in the literature, is slightly lower. For functionalized amines, this difference is much larger because amines favor the adsorption of $\mathrm{CO}_{2}$. However, because bimodal silicas are adsorbent and can be obtained simply with much cheaper materials, they are still very attractive for industry.

When it comes to higher pressures, bimodal silica demonstrated better efficiency compared to the results of Nascimento et al. (2014) [28], as described in Table 4.

Table 4. $\mathrm{CO}_{2}$ adsorption capacities obtained at higher pressures.

\begin{tabular}{ccc}
\hline Adsorbents & Adsorption Capacity $\mathbf{( m m o l \cdot g ^ { - 1 } )}$ & Reference \\
\hline $100 \mathrm{CO}_{2}$ & 9.10 & Author \\
$\mathrm{MCM}-48$ & 14.89 & Nascimento et al. (2014) \\
SBA-15 & 9.97 & Nascimento et al. (2014) \\
\hline
\end{tabular}

For high pressures, the present material was as good as the conventional SBA-15; it was slightly less functional than MCM-48 but still advantageous considering its flexibility, good thermal and chemical stability, and low-cost materials.

After adequate treatment of the data obtained from the microadsorbent, the $\mathrm{CO}_{2}$ adsorption equilibrium isotherms were then adjusted to the Langmuir and Freundlich theoretical models, as shown in Figure 8. 

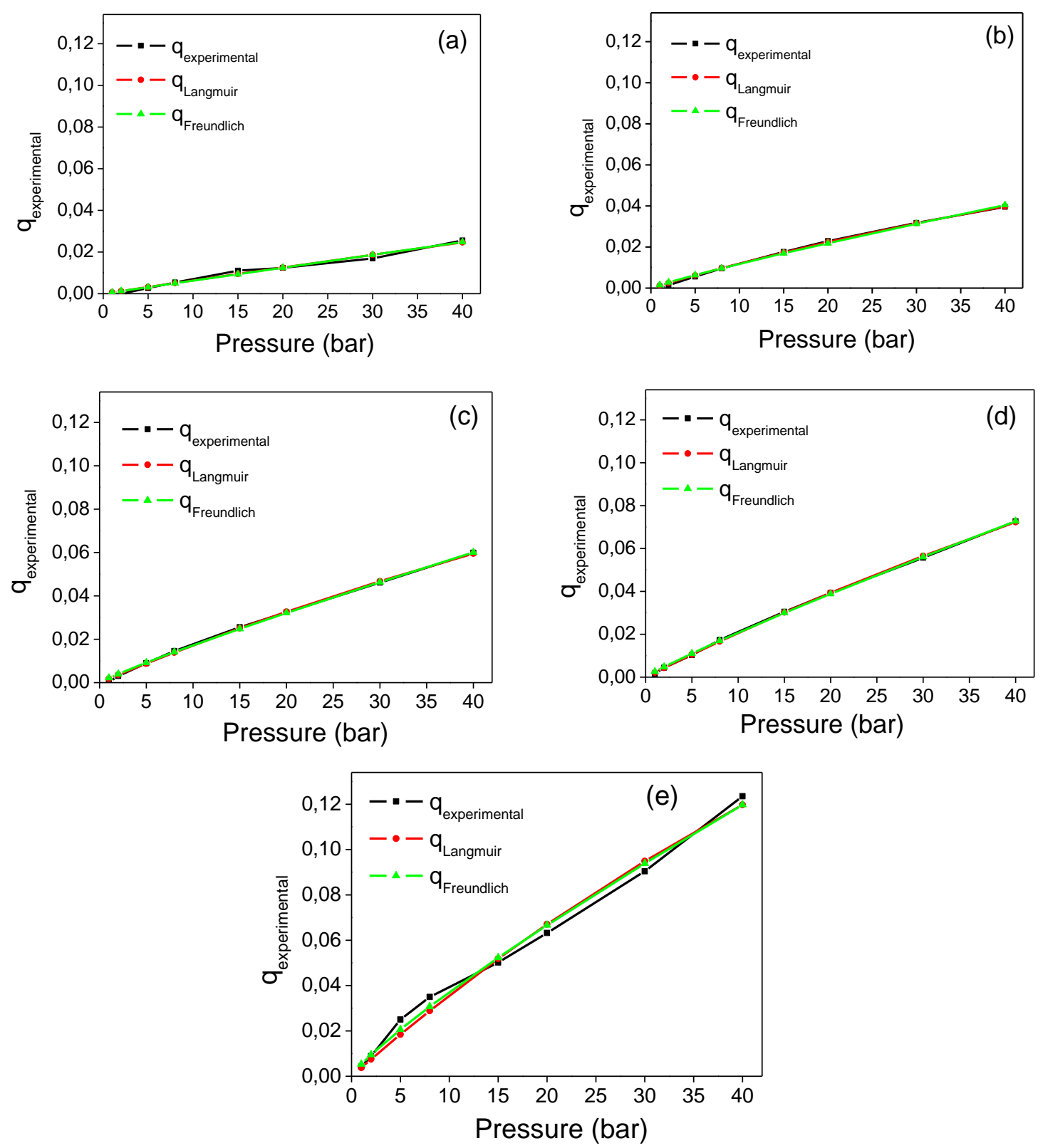

Figure 8. Comparison of isotherms of Langmuir and Freundlich Si12 (a) Si25 (b) Si36 (c) Si50 (d) and $\mathrm{SiCO}_{2}(\mathbf{e})$.

According to the results shown in Figure 8, for low pressure values (0 to 5 bar), all studied isotherms showed linear behavior, which characterizes the beginning of the monolayer formation [15,24]. For values greater than 5 bar, the isotherms presented a profile with a concave curve shape, which was more intense for the $100 \% \mathrm{CO}_{2}$ isotherm, thus ensuring that the adsorption of $\mathrm{CO}_{2}$ by the adsorbent is a favorable process.

The estimated parameters in this work for the proposed models are described in Table 5, including the maximum adsorption capacity $\left(\mathrm{q}_{\mathrm{m}}\right)$ and theoretical adsorption capacity in the monolayer (b), based on the Langmuir model; the solid adsorption capacity $\left(\mathrm{K}_{\mathrm{F}}\right)$ and the adsorption intensity parameter $(1 / n)$, based on the Freundlich model; and the linear regression coefficients $\left(R^{2}\right)$ for the isotherms. 
Table 5. $\mathrm{CO}_{2}$ adsorption capacities obtained at different pressures.

\begin{tabular}{ccccccc}
\hline Model & Parameters & Si12 & Si25 & Si36 & Si50 & SiCO $_{2}$ \\
\hline \multirow{3}{*}{ Langmuir } & $\mathrm{q}_{\mathrm{m}}(\mathrm{g})$ & 0.626 & 0.177 & 0.334 & 0.4419 & 0.560 \\
& $\mathrm{~b}(\mathrm{~L} / \mathrm{g})$ & 0.001 & 0.007 & 0.005 & 0.005 & 0.007 \\
& $\mathrm{R}^{2}$ & 0.98 & 0.99 & 0.99 & 0.99 & 0.98 \\
\hline \multirow{3}{*}{ Freundlich } & $\mathrm{K}_{\mathrm{F}}(\mathrm{L} / \mathrm{g})$ & 0.0006 & 0.00152 & 0.00216 & 0.00257 & 0.0053 \\
& $1 / \mathrm{n}$ & - & - & - & - & - \\
& $\mathrm{R}^{2}$ & 0.98 & 0.99 & 0.99 & 0.99 & 0.99 \\
\hline
\end{tabular}

According to Table 5, both models fit the experimental data under the applied conditions, presenting linear regression coefficients $\left(\mathrm{R}^{2}\right)$ in the range of $0.98-0.99$, indicating that $\mathrm{CO}_{2}$ adsorption was not restricted to the formation of the monolayer and showing that the material presented a surface with heterogeneous adsorption [28]. However, the Langmuir equation was better adjusted to the data obtained experimentally, presenting a qm with values closest to those obtained for the microadsorbent when compared to the Freundlich equation $\left(\mathrm{K}_{\mathrm{F}}\right)$.

We also observed an increase in the $\mathrm{CO}_{2}$ adsorption capacity (higher value of $\mathrm{q}_{\mathrm{m}}$ ) with an increase of its concentration in the gas mixture, thereby demonstrating the viability of using the adsorbent in any concentration of $\mathrm{CO}_{2}$, demonstrating that it can be easily applied to the necessary treatment of pre-salt NG, as proposed in the paper, because it has high concentrations of $\mathrm{CO}_{2}$. In addition to the results obtained, the excellent adsorption capacity of the material was proven compared to the literature results, presenting low pressure adsorption results close to commercial materials of the type MCM-41, which is inferior, according to the results obtained by Barbosa (2013) [19], compared to the SBA16 functionalized with amines [17], since the addition of amines increased the adsorbent potential due to the pure structure lacking active sites to promote interactions with carbon dioxide.

For higher pressures, the material was as good as conventional SBA-15 and slightly less functional than MCM-48 [28]. However, the material is still considered advantageous based on its properties that confer flexibility and good thermal and chemical stability. For the theoretical adjustments, both models fit the experimental data under the applied conditions, showing that the material presented a surface with heterogeneous adsorption [29].

\section{Conclusions}

The development of new hierarchical porosity-based silica-based materials for adsorption processes is a promising direction in nanoscience and nanotechnology. By analyzing the synthesis route used to obtain bimodal silica containing meso and macropores, it has been shown that n-decane hydrocarbon can be successfully used to obtain ordered porosity silica, as well as good particle distribution. The hydrothermal method and synthesis parameters, such as temperature, mixing time, and the amount of the driver, must be pre-adjusted to obtain bimodal silica.

Bimodal silica powder, obtained according to the pre-established parameters, was obtained with a specific surface area of about $230 \mathrm{~m}^{2} / \mathrm{g}$ and a pore distribution in a mesoporous $(2-5 \mathrm{~nm})$ and macroporus (greater than $50 \mathrm{~nm}$ ) range. The characterization of the material obtained through X-ray diffractometry, scanning electron microscopy, and infrared abortion spectroscopy showed that the amorphous silica material was obtained with ordered porosity in the meso and macropore range, which is considered bimodal, with typical bonds of silica (O-Si-O), silanols $(\mathrm{Si}-\mathrm{OH})$, and surface water $(\mathrm{H}-\mathrm{OH})$.

Regarding the adsorption of pure $\mathrm{CO}_{2}$, the present material is selective for adsorption only of $\mathrm{CO}_{2}$ and not of $\mathrm{CH}_{4}$, showing that it is an excellent adsorbent for Natural Gas, since $\mathrm{CO}_{2}$ is a contaminant that needs to be removed to meet the requirements and commercial parameters according to current legislation in the country. In the gas mixtures, the expected results were obtained, with an increase in the amount of adsorbed $\mathrm{CO}_{2} \mathrm{mmol}$ proportional to the increase of this gas in the gas mixture. 
We observed that the influence of gas pressure on adsorption is an important parameter for analysis, as there is a considerable increase in the adsorbed mass when there is an increase in system pressure. These results show the need to perform NG treatment by adsorption using bimodal silica at higher pressures (above 20 bar), which is an advantage when dealing with pre-salt NG. We also observed faster adsorption at pressures up to 5 bar, indicating behavior close to the linear model due to the greater availability of the active sites to these pressures. Additionally, we noticed an increase in $\mathrm{CO}_{2}$ adsorption capacity (higher value of $\mathrm{q}_{\mathrm{m}}$ ) with an increase of its concentration in the gas mixture, demonstrating the viability of using this adsorbent in any concentration of $\mathrm{CO}_{2}$ and indicating that it can be easily applied to pre-salt NG treatment. According to the results above, the proposed adsorbent is an excellent material for the treatment of natural gas and is proven to be effective for the removal of $\mathrm{CO}_{2}$ contaminants.

Author Contributions: Conceptualization, A.S.A.; Data curation, F.C.d.C. and P.F.d.N.; Formal analysis, F.C.d.C. and M.R.O.d.S.; Investigation, M.R.O.d.S.; Methodology, F.C.d.C.; Project administration, A.S.A.; Resources, F.C.d.C.; Supervision, A.S.A. All authors have read and agreed to the published version of the manuscript.

Funding: This research received no external funding.

Conflicts of Interest: The authors declare no conflict of interest.

\section{References}

1. Empresa de Pesquisa Energética. Brazilian Energy Balance 2017 Year 2016; Empresa de Pesquisa Energética: Rio de Janeiro, Brazil, 2017.

2. Araújo, O.R. Comparative analysis of separation technologies for processing carbon dioxide rich natural gas in ultra-deepwater oil fields. J. Clean. Prod. 2017, 155, 12-22. [CrossRef]

3. Petrobras Annual Report 2018. Available online: https://www.investidorpetrobras.com.br/ptb/206/Relatorio_ anual_27_03.pdf (accessed on 8 November 2019).

4. Brazil Ministry of Science, Technology, Innovation and Communication. Fugitive Emissions of Greenhouse Gases in the Oil and Natural Gas Industry. Reference Reports: Energy Sector. 2nd Brazilian Inventory of Anthropogenic Emissions and Removal of Greenhouse Gases; DF MCTI: Brasília, Brazil, 2010.

5. Machado, E. Low carbon economy: Assessment of impacts of restrictions and technological perspectives: Petroleum and petrochemistry. Available online: https://www.researchgate.net/publication/303693117_ economia_de_baixo_carbono_avaliacao_de_impactos_de_restricoes_e_perspectivas_tecnologicas_ petroleo_e_petroquimica (accessed on 20 October 2019).

6. Empresa de Pesquisa Energética. Occurrence of $\mathrm{CO} 2$ in Oil Fields on the Brazilian East Bank. Available online: http://www.epe.gov.br/sites-pt/publicacoes-dados-abertos/publicacoes/PublicacoesArquivos/publicacao322/OCORR\%C3\%8ANCIA\%20DE\%20CO2\%20EM\%20CAMPOS\%20PETROL\%C3\%8DFEROS\%20NA\% 20MARGEM\%20LESTE\%20BRASILEIRA.PDF (accessed on 20 December 2019).

7. Sugimoto, L. Research Measures Gas Emissions in Offshore Platforms. Available online: http://www. unicamp.br/unicamp/ju/661/pesquisa-mensura-emissao-de-gases-emplatforms-no-mar (accessed on 11 December 2019).

8. Gaffney, Cline \& Associates. Review and Evaluation of Ten Selected Discoveries and Prospects in the Pre-Salt Play of the Deepwater Santos Basin, Brazil. 2010. Available online: http://www.anp.gov.br/?dw=39137 (accessed on 3 December 2019).

9. Cruz-Navarro, D.S.; Torres-Rodríguez, M.; Mugica-Álvarez, V.; Gutiérrez-Arzaluz, M. Separation and Capture of $\mathrm{CO}_{2}$ through A Zeolitic Membrane. Proceedings 2018, 2, 1436. [CrossRef]

10. Santos, T.C.; Ronconi, C.M. $\mathrm{CO}_{2}$ Capture in Hybrid Materials. Rev. Virtual Quim. 2014, 6, 112-130. [CrossRef]

11. Leal, O.; Bolivar, C.; Ovalles, C.; Garcia, J.J.; Espidel, Y. Reversible adsorption of carbon dioxide on amine surface-bonded silica gel. Inorg. Chim. Acta 1995, 240, 183-189. [CrossRef]

12. Takahashi, R.; Sato, S.; Sodesawa, T.; Azuma, T. Silica with Bimodal Pores for Solid Catalysts Prepared from Water Glass. J. Sol Gel Sci. Technol. 2004, 31, 373-376. [CrossRef]

13. Benvenutti, E.V.; Moro, C.C.; Costa, T.M. Silica-based hybrid materials obtained by sol-gel method. Quim. Nova 2009, 32, 1926-1933. [CrossRef] 
14. Bacsik, Z.; Ahlsten, N.; Ziadi, A.; Zhao, G.; Garcia-Bennett, A.E.; Martín-Matute, B.; Hedin, N. Mechanisms and kinetics for sorption of $\mathrm{CO}_{2}$ on bicontinuous mesoporous silica modified with n-propylamine. Langmuir 2011, 27, 11118-11128. [CrossRef] [PubMed]

15. Lessa, M.D. Evaluation of $\mathrm{CO}_{2}$ Adsorption Capacity in $13 \mathrm{X}$ Zeolite with Synthetic Gases Originated from Sewage Sludge Pyrolysis. Master's Thesis, Technology Center, Department of Chemical Engineering, Federal University of Rio Grande do Norte, Natal, Brazil, 2012.

16. Sanz-Pérez, E.; Dantas, T.; Arencibia, A.; Calleja, G.; Guedes, A.; Araujo, A.S.; Sanz, R. Reuse and recycling of amine-functionalized silica materials for $\mathrm{CO}_{2}$ adsorption. Chem. Eng. J. 2017, 308, 1021-1033. [CrossRef]

17. Dantas, T.C. Synthesis and Characterization of Inorganic-Organic Mesoporous Materials for Application in Carbon Dioxide Adsorption. Ph.D. Thesis, Institute of Chemistry, Federal University of Rio Grande do Norte, Natal, Brazil, 2016.

18. Yu, J.; Le, Y.; Cheng, B. $\mathrm{CO}_{2}$ performance and adsorption of porous bimodal silica hollow spheres with amine modified surfaces. RSC Adv. 2012, 2, 6784-6791. [CrossRef]

19. Barbosa, M.N. Study of Mesoporous Materials Functionalized with Different Amines to Capture Carbon Dioxide Through the Adsorption Process. Ph.D. Thesis, Center for Exact and Earth Sciences, Institute of Chemistry, Federal University of Rio Grande do Norte, Natal, Brazil, 2013.

20. Oliveira, T.G.; Machado, S.W.; Santos, S.C.; Souza, M.J.; Pedrosa, A.M. $\mathrm{CO}_{2}$ adsorption in micro and mesoporous molecular sieves. Quím. Nova 2014, 37, 610-617. [CrossRef]

21. Silva, E.G. $\mathrm{CO}_{2}$ Adsorption Using Amine-Impregnated Mesoporous Material. Final Course Work. Available online: http://monografias.ufrn.br/handle/123456789/2043 (accessed on 11 December 2019).

22. Nascimento, P.F. Use of Metal-Containing Solid Waste from the Biomass Pyrolysis Process for $\mathrm{CO}_{2}$ Adsorption. Master's Thesis, Technology Center, Department of Chemical Engineering, Federal University of Rio Grande do Norte, Natal, Brazil, 2015.

23. Santamaría, E.; Maestro, A.; Porras, M.; Gutiérrez, J.M.; González, C. Preparation of structured meso-macroporous silica materials: Influence of composition variables on material characteristics. J. Porous Mater. 2014, 21, 263-274.

24. Nascimento, P.F.P.; Sousa, J.F.; Oliveira, J.A.; Possa, R.D.; Santos, L.S.; Carvalho, F.C.; Ruiz, J.A.C.; Pedroza, M.M.; Bezerra, M.B.D. Wood Sawdust and Sewage Sludge Pyrolysis Chars for $\mathrm{CO}_{2}$. Can. J. Chem. Eng. 2017, 95, 2148-2156. [CrossRef]

25. Zhang, G.; Xu, Y.; Xu, D.; Wang, D.; Xue, Y.; Su, W. Pressure-induced crystallization of amorphous $\mathrm{SiO}_{2}$ with silicon-hydroxy group and the quick synthesis of coesite under lower temperature. High Press. Res. 2008, 28, 641-650. [CrossRef]

26. Bezerra, D.P.; Oliveira, R.S.; Vieira, R.S.; Cavalcante, C.L.; Azevedo, D.C. Adsorption of $\mathrm{CO}_{2}$ on nitrogen-enriched activated carbon and zeolite 13X. Adsorption 2011, 17, 235-246. [CrossRef]

27. Neimark, A.V.; Sing, K.S.W. Characterization of Solid Catalysts. In Handbook of Heterogeneous Catalysts; Wiley-VCH Verlag: Weinheim, Germany, 2008.

28. Nascimento, A.R.; Figueredo, G.P.; Rodrigues, G.; Melo, M.A.; Souza, M.J.; Melo, D.M. Synthesis and characterization of nickel modified mesoporous materials for $\mathrm{CO}_{2}$ capture. Ceramics 2014, 60, 482-489. [CrossRef]

29. Heidari, A.; Younesi, H.; Rashidi, A.; Ghoreyshi, A.A. Evaluation of $\mathrm{CO}_{2}$ adsorption with eucalyptus wood based activated carbon modified by ammonia solution through heat treatment. Chem. Eng. J. 2014, 254, 503-513. [CrossRef]

(C) 2020 by the authors. Licensee MDPI, Basel, Switzerland. This article is an open access article distributed under the terms and conditions of the Creative Commons Attribution (CC BY) license (http://creativecommons.org/licenses/by/4.0/). 